\title{
The role of information technologies in organization of non- formal education
}

\author{
Irina Elkina ${ }^{1, *}$ and Natalia Shashkova ${ }^{2}$ \\ ${ }^{1}$ ISED RAE, Comparative Education Center, 105062, Moscow, Russia \\ ${ }^{2}$ State Museum of A.Pushkin, curator of the collection, 119034, Moscow, Russia
}

\begin{abstract}
The authors consider the role of information technologies in realization of non-formal education in the modern information society. Cultural and leisure institutions, libraries etc. become facilitators of non-formal education. Introduction to cultural values, to the new knowledge, obtaining positive emotions attracts the representatives of various professional and social groups to this kind of education and additionally favors their familiarization with the Humanities. A large choice of new, game forms and methods of training, learners' active participation - all this empowers non-formal education and a skill to learn and work under the conditions of redundant information is one of the most relevant in the modern society.
\end{abstract}

In the modern world information systems change extremely intensively and more actively penetrate into various spheres of human life, including education. The rate of these changes and involvement of a contemporary researcher into this process do not allow taking the position of an aloof observer. Having no time for comprehending certain challenges and giving an efficient answer for them, the scientist - philosopher, culturologist, pedagogue - encounters the other new ones. Thus several years ago, sometimes even now, we have to deal with the position that it is necessary to keep a coming generation from information technologies addiction. It seems that the world network is an embodiment of a global evil and the best thing for the developing personality is maximal limitation of the "contact" with this phenomenon. While the position of certain people and researchers is thus much inert, the system of education because of its large scale, multilevelness and slowness of the state management system even more cannot flexibly and rapidly meet the challenges of the time. Forming the new methods of training of not only the leaners but - firstly - of the teaching staff is the global and responsible task for the representatives of pedagogical science, more difficult because of the lack of the time for its realization [1]. The process of informatization, influencing the society so much, cannot be stopped; also there is no need to state that it is necessary to regulate it. We have to accept the fact that in the modern world information becomes more available and it updates so fast that educational programs, textbooks etc. not always have time to respond to its emergence. However we can state that information technologies influence forms and methods of teaching and learning outcomes assessment, therefore they become mediators of cognitive development, improving acquiring universal cognitive competences, necessary for the life in modern society [2].

In this paper, the authors attempt to consider positive experience of the development of various kinds of supplementary education, self-education, and educational leisure, which have become available due to information technologies. Firstly, it is important to pay attention to the fact that in Russia this experience is realized mainly by already formed but young enough people living in large cities. In our opinion, the result, which is achieved by this quite narrow - well-educated and progressive - layer without external regulators like state programs and educational institutions, is an interesting example for study and can be considered as a kind of naturally emerged experimental ground. The detailed studies, including collecting statistic data and a profound analysis, are the target for additional research. The full coverage of all aspects of the considered phenomenon is impossible in the frame of a short paper that is why we consider its objective in the designation of some spheres for the further research. We would like to emphasize that the paper does not discuss distant ways of getting vocational training and professional development as well as enhancing of research for professional scientists due to the use of Internet.

Until recently the notion "self-education" was associated firstly with reading and to a smaller extent visiting leisure facilities and organized or spontaneous "club" communication. In the new technologies epoch the possibilities of access to educational programs have been extended due to distance education. Distance education (sometimes called e-Learning) means a broad use of information technologies. Convenience of getting education at a free time, day or night at any available place (home, work, transport) is an incontestable

Corresponding author: inter@instrao.ru 
advantage of distance education. Specific means, connected with computer and telecommunication technologies use: special software tools and products, audio and video lectures, tutorials via Internet which can be organized both in real-time and in the form of emails in specialized chats and forums, imply more emphasis on learners' independent work [3]. The experience of a number of educational institutions, in particular, of the Open University of Great Britain, which was established even in 1969 as an educational institution offering exactly distant education, shows that the quality education in a distance form can be provided practically in all academic subjects [4]. Information and communication technologies ensure a new education environment which demands acquisition of new skills from learners. Critical thinking experience, research activity and assessment skills become priority as the learners have to deal with a very diverse and redundant content [5]. Herewith, the new information education environment changes not only the educational process itself, but the activity of a teacher and a learner in this process.

The teacher's role, once the only source of information, should change essentially; under the new conditions he/she should instruct a learner how to find, select, conceive and use the necessary information [6].

With the available redundancy of information content the learner's role changes as well. Once the "object" of the educational process, which was taught, and he/she passively hearkened instructions, now he/she becomes a competent active participant of educational process and he/she has to be able to learn in these conditions. By itself this statement is not new, however, what does it mean in information society? One of pedagogical trends - heutagogy, studying independent self-training of adults, notes that this skill includes not only independent search and mastery of a new knowledge, meeting interests and needs of the learner, but it also means choosing forms of education, designing, adjustment of educational process according to the learner's abilities and demands [7]. In this case the teacher plays the part of a coordinator, directing this process, a facilitator, making search and mastery of a new knowledge easier for the learner. Therefore, various participants of educational process have responsibility for its certain stages [8]. However, we should accentuate that the very striving of the learner for mastering a definite knowledge sphere, his/her responsibility for learning outcomes is the main motive power for such an educational process.

The ways of acquiring new knowledge and relations in interest groups also become infinitely varied as a result of a widespread introduction of information technologies into everyday life. Redundancy and variety of content allows the learner searching necessary information incidentally, setting connections with the other fields of knowledge, paving his/her own pass in this content. Information technologies allow him/her sharing results of search not only with the teacher, but with the other people interested in the same subject. Such an organization of education process was suggested by the educator and researcher Dave Cormier who called it "rhizomatic learning" [9] (he borrowed this name from the notion of "rhizome" introduced by J. Deleuze and F. Guattari [10]). United by common interests in groups, having profound intrinsic motivation for the new knowledge search, members of learning community independently, but in a constant interaction with each other, a teacher or a consultant from a professional community they work out a solution for the problem put for them. Herewith their learning is built up on the principles arising from peculiarities and descriptions of rhizome by Deleuze and Guattari. The principle of individualization of the learning pathway means that the learner chooses himself, which way he uses to find new information, masters it and turns into his knowledge. The principle of continuing education allows ceasing educational process at any time; however it allows starting it from any level and at any moment. The principle of integrity and indivisibility of content at the meta-level gives the possibility for search in any direction at any level of complexity of knowledge. The principle of independent learning based upon profound intrinsic motivation is the foundation for this kind of learning, we mean here the responsibility, which the learner takes choosing the program, level of complexity of education etc. [11].

This education is possible in the open postindustrial society, which is oriented to develop moral and cultural aspects of life [12], when every learner has the possibility to choose the field of knowledge necessary or interesting for him at the moment. Foreign experience shows that the local community, businesses and educational institutions interested in an intake of consumers or audience can offer this choice. This education provides learning for an individual for the realization of his/her cultural goals [13]; in this case it means that there should be no obstacles in getting this education for the learners. In practice this model should be connected with implication of modern means of communication and distance education. The learners should make decisions by themselves to get education and where and which way to do it.

Practically this kind of learning is realized at various courses of online lectures, which are offered by the world leading universities and scientific research centers. These mass open online courses - MOOC - began their active development less than ten years ago. Higher School of Economics, Novosibirsk State University, Internet-portal "Education in Russian", established by the State Institute of the Russian Language named after A.S. Pushkin with the support of the Ministry of Education and Science of the RF, and several other educational institutions offer these courses in Russia [14]. There are special educational resources combining materials from various sources. They include, for instance, Internet portals for those who study foreign languages, professional Internet-associations of interpreters, free consulting forums of native speakers etc. There are online courses, focused on forming social skills for citizens (for instance, on the State services portal of Moscow). In certain cases students are to take exams and get certificates upon completion of their training. Here we deal with the forms of tuition, which look like the system of Western European university 
education, where the learner feels free to form a certain part of his/her curriculum, taking into account his/her own interests or teacher's personality when choosing the course of studies.

Conditionally we can include into the same group virtual excursions and lectures, available at web-sites of museums, theatres and libraries. The most widely spread and popular are leisure and educational projects in the sphere of culture, art, history and local lore. On one hand, familiarization with cultural values, presenting both new knowledge and bright emotions, is attractive for the representatives of various professional and social groups, and expanding horizons for many people traditionally correlates with familiarization with humanitarian knowledge. On the other hand, events, aimed to popularization of technical and natural scientific knowledge, need special conditions and resource base that is why they are realized by museums, higher educational institutions and other organizations having necessary resources.

There is a number of public-service and private organizations in the sphere of protection and promotion of cultural heritage, which operate at the intersection of real and virtual space. Among the most popular ones we can mention Archnadzor (Architectural Supervision) and Shkola Naslediya (The School of Heritage), DOCOMOMO (The Russian branch of international working group for documentation and conservation of buildings and sites), "Moscow, which has never existed", Moskvahod (The Society of Walking Tours in Moscow), although there are many other wonderful initiatives, which simply cannot be described and mentioned in this paper. Internet is used for advertising, planning and events co-ordination, posting reviews and discussions, thematic advertising etc. At the same time real peopleto-people interaction takes place in the form of various excursions and walking tours, lectures and discussions in more or less formal atmosphere, joint trips, exhibitions and social events.

As a rule, experts participating in these events have a certain state and personal popularity in a community, have active stand in life and are not confined by the cooperation with official web-sites. They create their own author's online resources, have social networks and "LiveJournal" web-pages, appear on TV, radio, mass media and publish their papers in scientific journals. As a result there appear complicated conglomerations of various types of activities in the information environment and real life, which are kept up by the system of Internet cross-references and participation in the joint educational and practical activity. These conglomerations attract an increasing number of participants each of which can join the community on convenient terms, and this practice merely testifies the viability of rhizomatic learning.

We should mention one more trend: gradual expansion of the range of noteworthy phenomena interesting from the educational viewpoint, cookery, traditions, mentality, forms of communication typical for other regions, culture, social groups being among them. Modern information environment offers a wide range of ways for realizing these interests either separately or in various combinations. There are internet communities for seeking variants of travel exchange and companions for travelling, engagement of a voluntary free guide from local residents, mutual aid of native speakers for those, who learn foreign languages, etc. There is a special type of a learning project of this subject matter called "human library", when the representatives from various social groups and rare professions narrate about peculiarities of their life for all, who are interested in it, and answer their questions in a personal communication. In this case Internet has a coordination function.

In certain cases cognitive component enriches those kinds of leisure, which seemingly are not connected with education. Then there appeared an idea of a group bike ride to mark a bicentenary of the Patriotic War of 1812 from the Borodino village to Paris following the way of retreat of Napoleon's army from Russia.

It is necessary to mention the involvement into leisure-educational programs, which eventuates in Internet by different ways. The most traditional way is a targeted search and joining into interest groups, however, we cannot help taking into account the other forms with the element of chance in their creation. For example, announcements and notices about events obtained from social networks where information spreads by a number of intersecting channels, take a form of random sample from numerous variants. One of the recent examples is the high popularity (especially among the young people) of world-known masterpieces of fine art taking place in Moscow museums. Photo reports and text comments of the visitors exactly in social networks play an important part in their popularization. Forming communities based on geolocation data is popular as well: an individual can contact with the other people, who are in close proximity to him/her and who are ready to communicate, or with those, who visit regularly the same places/events. Therefore, the number of potential contacts becomes practically unlimited. Practicing psychologists actively interpret these contemporary ways of communication establishing. There are a number of recommendations and trainings to use the new communication facilities for expanding the range of personal and business contacts, looking for a spouse or a sexual partner. However, the use of these technologies in educational sphere is much less comprehended to the best of authors' knowledge.

A very interesting and important feature of educational leisure at the intersection of real and information space is the fact that sometimes it is perceived as a gambling adventure. The process of search for the new knowledge is exposed to the introspection and is described together with the outcomes achieved. As a rule, Internet discussion is opened up on the subject, its new aspects are revealed and new results are achieved. Cognitive quests are the organized game form of "the hunt for knowledge", transferred into the real life. Education development foresights $([15,16,17])$ show that education gamification will replace traditional education. Game plot favours creation of the feeling of participation, interest to achieving goals set for a certain game stage or 
level. Moreover, the goals and objectives change and become more complex while the users gain new skills.

From this, hence, it follows that a successful and efficient use of information technologies for the purpose of self-development and self-education is impossible without a high cognitive motivation, which can be formed only in direct communication of tutor and developing learner's personality - in the broadest sense of these notions - irrespective of the way of their communication. To learn how to live in the modern information environment and to withstand its threats, to keep humanistic values and enjoyment of genuine real life is a precious and important personal experience for each of us. To achieve the same in the scope of the system of education and society as a whole is undoubtedly one of the global challenges of modernity.

\section{References}

1. S.V. Ivanova, Tsennosti i smysly, 2, 4-17 (2012) [In Rus]

2. S. Noor-Ul-Amin, An Effective use of ICT for Education and Learning by Drawing on Worldwide Knowledge, Research, and Experience: ICT as a Change Agent for Education (a literature review). Available at

URL: www.nyu.edu/classes/keefer/waoe/amins.pdf. (Date of access 23.02.2016).

3. R. Mason, The Internet and Higher Education, 3, 6374 (2000).

4. Innovating Pedagogy. Available at URL: http://www.open.ac.uk/iet/main/sites/www.open.ac. uk.iet.main/files/files/ecms/webcontent/Innovating_Pedagogy_report_July_2012.pdf (Date of access: 10.12.2014).

5. New Media Consortium. Horizon Report. Available at URL: www.nmc.org/pdf/2007_Horizon_Report.pdf (Date of access: 12.01.2016).

6. P. Freire, Pedagogy of Freedom. Ethics, Democracy and Civic Courage. Available at URL: www.goodreads.com/.../86881.Pedagogy_of_Freedo $\mathrm{m}$. (Date of access: 11.06.2015).
7. S.A. Dudko, PhD Thesis (Moscow, 2013) [In Rus]

8. A.K. Jager and A.H. Lokman, Impact of ICT on education. The role of the teacher and teacher training (Lahti, 1999).

9. D. Cormier, Rhizomatic Education: Community as Curriculum. Available at URL: http://davecormier.com/edblog/2008/06/03/rhizomat ic-education-community-as-curriculum/ (Date of access: 28.04.2015).

10. J. Deleuze and F. Guattari, A Thousand Plateaus (London and New York, Continuum, 2004).

11. I.M. Elkina, Nauka i shkola, 2 (2016) [In Rus]

12. Lifelong Learning: Patterns of Policy in Thirteen European Countries. (Ljubljana, 2007).

13. J. Mezirow, Learning as Transformation: Critical Perspectives on a Theory in Progress (Jossey Bass, San Francisco, 2000).

14. Novosibirskiy gosudarstvennyi universitet. Available at URL: http://www.nsu.ru/2d868196abde02c0b2162954105 32973 (Date of access: 22.02.2016) [In Rus]

15. The Foresight Education and Research Network. Available at URL: http://www.fernweb.org/\#! foresightresources/cfvg (Date of access: 02.03.2016).

16. Forsait "Obrazovanie 2035". Available at URL: http://asi.ru/molprof/foresight/12254/ (Date of access: 02.03.2016) [In Rus]

17. Forsait "Obrazovanie-2030". Available at URL: http://metaver.net/2011/edu2030/ (Date of access: 02.03.2016) [In Rus] 